\title{
Anesthetic Management of Tracheobronchial Foreign Body Aspiration Cases in Children
}

\author{
Jaldeep B Patel', Arunkumar Chauhan ${ }^{2}$ \\ ${ }^{1}$ Assistant Professor, Department of Anaesthesia, Government Medical College, Bhavnagar, Gujarat, India, ${ }^{2}$ Tutor, Department of Anaesthesia, \\ Government Medical College, Bhavnagar, Gujarat, India.
}

\section{Abstract}

Background: Foreign body aspiration is one of the most common emergencies in paediatrics and is a leading cause of mortality and morbidity in otherwise normal and healthy children. Present study analyses the anaesthetic management and outcome of tracheobronchial foreign body cases in paediatric age group in a span of one year in a tertiary care paediatric hospital setting. Subjects and Methods: Present retrospective study was conducted in patients subjected to diagnostic and therapeutic bronchoscopy for suspected foreign body removal from March 2017 to April 2018. The subjected data was collected as per age, sex, suspected history of foreign body aspiration, clinical features and their duration, location and type of foreign body based on physical examination and radiological evaluation, anaesthetic management and outcome, Intraoperative and postoperative complications if any, postoperative mechanical ventilation if required. All children underwent bronchoscopy using Storz rigid bronchoscope. Results: Seventy two cases underwent bronchoscopy, in 08 cases esophagoscopy was done, 30 patients underwent laryngoscopy out of which one patient required esophagoscopy as well. In $84.1 \%$ cases we were able to retrieve foreign bodies, while $15.9 \%$ had negative bronchoscopy. $32 \%$ patients had vegetative foreign bodies and most common in these were peanuts. Coin was the most common non-vegetative foreign body retrieved during laryngoscopy. On bronchoscopy it was discovered that the most common site of lodgement of foreign bodies was in right main bronchus followed by left main bronchus. Conclusion: Tracheobronchial foreign bodies are frequently observed in young children with serious life threatening effects. There is need for preventive measures including parental education and awareness.

Keywords: Bronchus, Bronchoscopy, Mechanical ventilation, Tracheobronchial foreign bodies.

Corresponding Author: Dr Arunkumar Chauhan, Department of Anaesthesia, Government Medical College, Bhavnagar, Gujarat, India.

Received: September 2019

Accepted: September 2019

\section{Introduction}

Foreign body aspiration is one of the most common emergencies in paediatrics and is a leading cause of mortality and morbidity in otherwise normal and healthy children. ${ }^{[1]} \mathrm{It}$ can be life threatening and if not properly managed can lead to chronic lung injury and a lot of psychological stress to the child and family. ${ }^{[2]}$ Poor chewing ability, less airway protection reflex, adventurous nature, lack of molars for proper mastication, habit of exploring objects with mouth, and eating while crying or playing are probable reasons in children for being prone to foreign body inhalation. ${ }^{[3]}$ Children mostly in the preschool age group out of curiosity, lack of the ability to assess the danger and lack of parental supervision can contribute to this hazard. Early diagnosis and the successful removal of the inhaled foreign material are associated with effective reduction in complications and mortality.

Historically, Gustav Killian was the first to use the rigid bronchoscopy method in 1897 to remove a foreign body from the right main bronchus which through the subsequent development of the bronchoscopic techniques lead to the observed reduction in the rate of mortality. ${ }^{[4,5]}$ With advances in the anaesthetic technique, rigid bronchoscopy has come to be performed under general anaesthesia. Use of the flexible bronchoscope was started in the 1970s, especially for the removal of aspirated foreign material localised in the distal airways. ${ }^{[6,7]}$ In most these cases rigid bronchoscopy has to be performed for the differential diagnosis of suspected tracheobronchial foreign body. Sharing of the airway by both the anaesthesiologist and surgeon makes bronchoscopy a challenging affair requiring a careful planning and better communication skills between both the anaesthesiologist and surgeon.8 Present study analyses the anaesthetic management and outcome of tracheobronchial foreign body cases in paediatric age group in a span of one year in a tertiary care paediatric hospital setting.

\section{Subjects and Methods}

Present retrospective study was conducted in patients subjected to diagnostic and therapeutic bronchoscopy for suspected foreign body removal from March 2017 to April 2018. The subjected data was collected as per age, sex, suspected history of foreign body aspiration, clinical features 
and their duration, location and type of foreign body based on physical examination and radiological evaluation, anaesthetic management and outcome, Intraoperative and postoperative complications if any, postoperative mechanical ventilation if required. All children underwent bronchoscopy using Storz rigid bronchoscope.

\section{Inclusion criteria}

History of FBA, presence of TFB on bronchoscopy, recurrent cough, or dyspnea. Exclusion criteria were as follows: patients with nasopharyn $\neg$ geal, hypopharyngeal, and esophageal FBs; evidence of asthma, and age above 15 years.

\section{Anaesthetic Management}

General anaesthesia is always the technique of choice for the removal of a tracheobronchial foreign body in a fighting irritable child, distally lodged invisible foreign body and if prolonged bronchoscopy procedure is contemplated. The problems of in many of these children is that of full stomach and the necessity for the both the surgeon and the anaesthesiologist to share the same airway. Nitrous oxide should be withheld to limit further pulmonary inflation and potential rupture. Rigid ventilating bronchoscope equipped with an optical telescope and fibrooptic light source has been used, in all of our patients.

After receiving the child in pre operative area, no child received any premedication. After securing a good intravenous access, children were induced with injection (inj) Thiopentone $3-4 \mathrm{mg} / \mathrm{kg}$ intravenous (IV), along with oxygen with sevoflurane. For muscle relaxation inj succinylcholine $1.5 \mathrm{mg} / \mathrm{kg} \mathrm{IV}$ was administered and repeated as required with a maximum dose of $5 \mathrm{mg} / \mathrm{kg}$ and lidocaine spray $2-3 \mathrm{mg} / \mathrm{kg}$ was used in all children to facilitate bronchoscopy and prevent laryngospasm. Inj propofol boluses were used for maintenance of anaesthesia. Injection Dexamethasone $0.5 \mathrm{mg} / \mathrm{kg} \mathrm{IV}$, humidified oxygen, inj Hydrocortisone 2 $\mathrm{mg} / \mathrm{kg}$ IV and nebulisation with bronchodilators was given in all our patients prophylactically. Patients were monitored continuously by pulse oximetry, NIBP and ECG.

Our main goals were to ensure adequate oxygenation, rapid return of airway reflexes, to prevent any laryngospasm, controlled cardiorespiratory reflexes. In all patients, as per institutional protocol chest $\mathrm{x}$-ray was taken 6 hours post operatively to assess lung expansion, to exclude pneumothorax and residual foreign body, if any.

\section{Statistical analysis}

The data was coded and entered into Microsoft Excel spreadsheet. Analysis was done using SPSS version 15 (SPSS Inc. Chicago, IL, USA) Windows software program. The variables were assessed for normality using the Kolmogorov-Smirnov test. Descriptive statistics were calculated.

\section{Results}

Total 110 cases of suspected foreign body in airway required removal under anaesthesia in a span of one year, out of which 84 cases were of acute onset and 26 cases presented with prolonged duration of symptoms. Majority of the participants were males and. more than $50 \%$ of these was in the age group below 3 years of age [Table 1].

78 of the 110 cases came for emergency intervention, rest were posted as elective ones. 83 out of the 110 cases commonly had cough and other prodromal features, out of which 56\% had respiratory distress as well. 72 cases underwent bronchoscopy, in 08 cases esophagoscopy was done, 30 patients underwent laryngoscopy out of which one patient required esophagoscopy as well. In $84.1 \%$ cases we were able to retrieve foreign bodies, while $15.9 \%$ had negative bronchoscopy. $32 \%$ patients had vegetative foreign bodies and most common in these were peanuts. Coin was the most common non-vegetative foreign body retrieved during laryngoscopy.

On bronchoscopy it was discovered that the most common site of lodgement of foreign bodies was in right main bronchus followed by left main bronchus [Table 2], while coin/ disc batteries were retrieved in 38 patients with laryngoesophagoscopy. More than $95 \%$ of the patients had some amount of laryngeal edema and approximately $72.1 \%$ had hoarseness of voice post procedure which subsided in due course of time. Almost 43 patients developed either desaturation upto $\mathrm{SpO} 280 \%$ or bradycardia during the procedure which was treated with adequate oxygenation and assisted ventilation with $100 \%$ oxygen. Of all the patients, 14 patients required intubation during or post procedure. 10 patients required postop ventilation and icu care, mostly these patients also had significant stridor and desaturation in preoperative period also, out of which 03 were already intubated in preoperative period itself. 03 patients who were already intubated in preoperative period and had negative bronchoscopies. In 01 patient foreign body was dislodged into stomach with esophagoscopy and was later retrieved per rectally. 01 patient each developed subcutaneous emphysema, seizures and choking.

Table 1: Age wise distribution of study participants

\begin{tabular}{|l|l|l|}
\hline Age in years & Number & Percentage (\%) \\
\hline$<1$ & 21 & 19.09 \\
\hline $1-3$ & 37 & 33.63 \\
\hline $3-5$ & 30 & 27.27 \\
\hline$>5$ & 22 & 20 \\
\hline
\end{tabular}

Table 2: Location of foreign body in the airway

\begin{tabular}{|l|l|l|}
\hline $\begin{array}{l}\text { Foreign body } \\
\text { location }\end{array}$ & Number & Percentage (\%) \\
\hline $\begin{array}{l}\text { Right main bronchus } \\
\text { (RMB) }\end{array}$ & 37 & 33.6 \\
\hline $\begin{array}{l}\text { Left main bronchus } \\
\text { (LMB) }\end{array}$ & 28 & 25.4 \\
\hline Cricopharynx & 21 & 19 \\
\hline $\begin{array}{l}\text { Left lower bronchus } \\
\text { (LLB) }\end{array}$ & 9 & 8.1 \\
\hline Trachea & 5 & 4.5 \\
\hline Esophagus & 3 & 2.7 \\
\hline LMB \& Trachea & 5 & 4.5 \\
\hline RMB \& Trachea & 2 & 1.8 \\
\hline
\end{tabular}

\section{Discussion}

Anaesthesia for rigid bronchoscopy in infants and children is a challenging procedure for paediatric anaesthesiologists, since it is often difficult to maintain the airway for adequate 
ventılation and oxygenation in patients whose pulmonary gas exchange is already reduced. Since the mid 1970s, Chavelier Jackson bronchoscopes have been replaced by newer types of bronchoscopes with a breathing sidearm. The use of Hopkins glass rod telescopes through the bronchoscope lumen has further reduced the airway patency and ventilation during bronchoscopy, especially in young children. Thus it has become extremely important to have a close dialogue with the bronchoscopist for the process of planning of the anaesthesia. ${ }^{[9]}$ The curiosity to explore things by mouth and lack of adequate supervision is the main reason for foreign body aspiration in the age group of 1-3 years. History of choking during eating is also significant during history taking. Our analysis of tracheobrochial foreign body confirms the findings of other studies that majority of the children presenting with foreign body aspiration were under the age of 3 years. ${ }^{[10-12]}$ In our study More than half of the children were below the age of 3 years. The natural urge to explore the objects by mouth, lack of molar teeth to crush nuts, crying and playing while eating and lack of parental supervision contributes to this hazard in this age group. Also the incidence is almost twice more common in males as compared to females, which is in accordance with the previous studies. ${ }^{[13,14]}$ Most common location is in right main bronchus followed by left which is in concurrence with the earlier studies. ${ }^{[14-16]}$ It occurs commonly in the right main bronchus than the left and less frequently in the larynx and trachea, this is because of anatomical position of right main bronchus, as it is more vertical and has larger diameter leading to more airentry than the left bronchus. In our study the common site for foreign body lodgement was right main bronchus followed by left main bronchus which is also found in study done by others. ${ }^{[17,18]}$

The bronchoscopies / esophagoscopies performed were either diagnostic or therapeutic, majority being emergency procedures with general anaesthesia as the preferred technique. ${ }^{[19]}$ Proper preanaesthetic assessment done in all the cases- bilateral air entry checked with focus on the location of the foreign body and the degree of airway obstruction, chest X-ray examined in order to determine the location of foreign body and to rule out secondary pathological changes like atelectasis, airtrapping or pneumonia, history of medical ailments elicited if any, preoperative oxygen saturation assessed, risk/high risk explained and written informed consent taken by parents/guardians.

In stable children preferred technique is intravenous induction. For muscle relaxation succinylcholine boluses are used as it is short acting, allowing controlled ventilation, allows less use of anaesthetic agents, prevents coughing and trauma and facilitates removal of foreign bodies through the vocal cords. All the patients were given $100 \%$ oxygen which was delivered through the sidearm of the bronchoscope by intermittent ventilation, sometimes requiring high flows of oxygen to compensate for the leak around the bronchoscope. However ventilation was also interrupted during suctioning and removal of foreign body. ${ }^{[18]}$

Anaesthesia maintenance was done with intermittent boluses of inj propofol and muscle relaxation with boluses of inj succinylcholine upto a maximum of $3 \mathrm{mg} / \mathrm{kg}$. On completion of the procedure, once the bronchoscope is removed from the patients' airway, all the patients were given bag and mask ventilation with $100 \%$ oxygen. ${ }^{[20]}$ Immediate post procedure, all patient received nebulization with bronchodilator with oxygen by face mask, patients are kept under observation in postoperative recovery area for stridor, respiratory distress or other signs of subglottic edema, bronchospasm. In our study 10 (ten) patients required intubation during or post procedure. 08(eight) patients required postoperative ventilation and ICU care, mostly these patients also had significant stridor and desaturation in preoperative period also and they had long standing history of foreign body of $>2$ weeks.

Organic foreign bodies like groundnut/ peanut/ coconut soften because of the secretions and generally break during their removal. In these cases larger pieces were extracted with the help of bronchoscopy forceps and very small pieces are removed with through suctioning. In some cases only mucous plugs were removed and no foreign bodies were retrieved. Coin and disc batteries lodged in cricopharynx were removed with laryngoscopy and magill's forceps using only boluses of inj propofol. One child had an elliptical shaped bead which was lodged in the right main bronchus. Because of the smooth surface of the bead it was difficult to catch and hold it with the telescopic forceps. Finally, through the opening of the bead, one small size Fogarty catheter was passed and once its balloon was distal to the bead, its balloon was inflated and the bead was removed along with the bronchoscope and the catheter.

After the bronchoscopy, the child is observed in a anaesthesia recovery room for stridor, respiratory distress or other signs suggestive of subglottic edema, damaged teeth, haemorrhage, bronchospasm and airway perforation. A chest radiograph should be obtained following bronchoscopy to exclude the presence of pneumothorax or mediastinal emphysema from barotraumas. ${ }^{[21]}$ Detail clinical history, Xray chest with proper surgical and anaesthetic management are essential to ensure a high degree of success rate.

\section{Conclusion}

Tracheobronchial foreign bodies are frequently observed in young children with serious life threatening effects. There is need for preventive measures including parental education and awareness. If not witnessed, treatment for inhaling foreign materials can be delayed as the symptoms are often nonspecific. Suspicious history and symptoms should be taken seriously and bronchoscopy should be performed in order to ensure early treatment and to reduce the development of probable complications including mortality. Bronchoscopy should be performed under optimal conditions after planning by experienced and well cooperating surgical and anaesthetic teams. Thorough and detailed clinical history, proper clinical assessment including chest X-ray, prompt and proper preoperative and perioperative anesthetic and surgical management ensure safe and successful recovery and outcome.

\section{References}

1. Blumhagen JD, Wesenberg RL, Brooks JG, Cottan EK. Endotracheal foreign bodies: Difficulties in diagnosis. Clin Paediatr 1980;19:480-484. 2. Burton EM, Brick WG, Hall JD. Tracheobronchial foreign body 
aspiration in children. South Med J 1996;89:195-198.

3. Liang $\mathrm{J}, \mathrm{Hu} \mathrm{J}$, Chang $\mathrm{H}$. Tracheobronchial foreign bodies in children: a retrospective study of 2,000 cases in Northwestern China Ther Clin Risk Manag 2015;11:1291-5.

4. Clerf LH. Historical aspects of foreign bodies in the air and food passages. South Med J 1975;68:1449-54

5. Robinson CL, Mushin WW. Inhaled foreign bodies. $\mathrm{Br}$ Med J 1956;2:324-8.

6. Dikensoy O, Usalan C, Filiz A. Foreign body aspiration: clinical utility of flexible bronchoscopy. Postgrad Med J 2002;78:399-403.

7. Hsu AA. Endoscopic intervention of lower airway foreign matter in adults-a different perspective. J Thorac Dis 2015;7:1870-7.

8. Pinar K. The anaesthetic consideration of tracheobronchial foreign body aspiration in children. J Thorac Dis 2016;8(12):3803-3807.

9. Mutogama EK, Davis PJ. Anaesthesia for Ear, Nose and Throat Surgery. In: Smith's Anaesthesia for Infants and Children, 6th edition 1996; 669-74.

10. Carluccio F, Romeo R. Inhaling foreign bodies: An epidemiological, clinical study of 92 cases. Acta Otorhinolaryngol Ital 1997; 17(1): 4551 .

11. Ashoore A, Baraka M, Kholania E. Foreign bodies in paediatric tracheobrochial tree. Saudi Med J 1987; 5: 481-86.

12. Siddiqui MA, Banjar AH, Al-Najjar SM. Frequency of tracheobronchial foreign body in children and adolescents. Saudi Med J 2000; 21: 36871.

13. Weissberg D, Schwartz I. foreign bodies in the tracheobronchial tree. Chest 1991;5:730-733.

14. Aravind Sehgal, Varinder Singh, Jagadish Chandra N, N. Mathur. Foreign body aspiration. Indian paediatrics 2002; 39: 1006-10.

15. Wiseman NE. The diagnosis of foreign body aspiration in childhood. J Pediatr Surg 1984;19:531-535.

16. D. Agarwal et al. Management of foreign bodies in tracheobronchial tree in paediatric age group- A brief review. Indian J Anaesth 2001;45(5):348-349.

17. Wiseman NE. The diagnosis of foreign body aspiration in childhood. J Pediatr. Surg 1984; 19: 531-35.

18. D. Agarwal et al. Management of foreign bodies in tracheobronchial tree in paediatric age group - A brief review. Indian J. Anaesth. 2001; 45(5): 348-49.

19. Black RE, Johnson DG, Matlak ME. Bronhoscopic removal of aspirated foreign bodies in children. J Pediatr Surg 1994; 29: 682-84.

20. Kalyanappagol VT, Kulkarni NH, Bidri LH. Management of tracheobronchial foreign body aspirations in paediatric age group- A 10 year retrospective analysis. Indian J Anaesth 2007;51(1):20-23.

21. GA. Gregory. Anaesthesia for Thoracic surgery. In: Paediatric Anaesthesia, 4 th edition. 2002; 449-51.

Copyright: () the author(s), publisher. Academia Anesthesiologica International is an Official Publication of "Society for Health Care \& Research Development". It is an open-access article distributed under the terms of the Creative Commons Attribution Non-Commercial License, which permits unrestricted non-commercial use, distribution, and reproduction in any medium, provided the original work is properly cited.

How to cite this article: Patel JB, Chauhan A. Anesthetic Management of Tracheobronchial Foreign Body Aspiration Cases in Children. Acad. Anesthesiol. Int. 2019;4(2):214-217.

DOI: dx.doi.org/10.21276/aan.2019.4.2.49

Source of Support: Nil, Conflict of Interest: None declared. 